\title{
Anorectal avulsion: an exceptional rectal trauma
}

\author{
Karim Ibn majdoub Hassani*, Said Ait laalim, El Bachir Benjelloun, Imane Toughrai and Khalid Mazaz
}

\begin{abstract}
Anorectal avulsion is an exceptional rectal trauma in which the anus and sphincter no longer join the perineum and are pulled upward. As a result, they ventrally follow levator ani muscles. We present a rare case of a 29-years old patient who was admitted in a pelvic trauma context; presenting a complete complex anorectal avulsion. The treatment included a primary repair of the rectum and a diverting colostomy so as to prevent sepsis. Closure of the protective sigmoidostomy was performed seven months after the accident and the evolution was marked by an anal stenosis requiring iterative dilatations.
\end{abstract}

Keywords: Anorectal avulsion, Rectal trauma, Surgical management

\section{Introduction}

Anorectal avulsion is an exceptional rectal trauma. In this kind of lesions, the anus and sphincter no longer join the perineum and are pulled upward. They are in addition ventrally following levator ani muscles. The management of this kind of lesions remains a matter of great debate. Early repair of the rectum, diverting colostomy, wound debridement, distal rectal wash-out are the most important procedures that help prevent sepsis. In addition, the colostomy closure can only be performed after pelvic rehabilitation in order to prevent transitory incontinence.

\section{Observation}

A 29-years-old patient was admitted to the emergency room (ER) of the University hospital Hassan II of Fez after having an accident which resulted in a severe pelvic trauma. When the patient was admitted to the ER, he was agitated but conscious and hemodynamically stable with slightly discolored conjunctives. The physical examination revealed a pulse rate of 90 beat per minute, a blood pressure of 110/80 $\mathrm{mmHg}$, but there was no fever. Abdominal examination showed minimal tenderness in the hypogastria with a distended bladder. Urologic examination revealed urethral bleeding with a large scrotal scar. The perineal exam showed a big substance loss with complete anorectal avulsion due to the contraction

\footnotetext{
* Correspondence: ibnmajdoubkarim@gmail.com Department of Surgery, School of Medicine and Pharmacy of Fez, Sidi Mohammed Ben Abdellah University, BP: 1893; Km2.200, Route de Sidi Hrazem, Fez 30000, Morocco
}

of the elevator ani muscle (Figure 1). Laboratory data showed a white-blood cell count of $10900 / \mathrm{mm} 3$, serum hemoglobin concentration of $10,4 \mathrm{~g} / \mathrm{dl}$ with a normal blood platelet level $(390,000 / \mathrm{mm} 3)$, a blood urea of $0.45 \mathrm{~g} / \mathrm{l}$ and a creatinine level of $10 \mathrm{mg} / \mathrm{L}$. Hemostasis laboratory data, chemistry and serum lipase were within normal limits. So, being hemodynamic stable, the patient underwent chest X-ray. The latter was normal. The pelvic $\mathrm{X}$-ray showed a right ischio pubic rami fracture (Figure 2). A contrast-enhanced computed tomography (CT) was performed and therefore showed a pelvic trauma with right ischio pubic rami fracture (Figure 3 ) as well as a fracture in the right transverse process of L5 and S1 sacral wing. CT scan also showed a right bladder effusion extending to the retro peritoneal area. Furthermore, there was a large inguinal hematoma measuring $10 \times 4 \mathrm{~cm}$ and fusing along the right thigh. It was therefore associated with symphysis emphysematous soft tissue extending down to the scrotum the thing that resulted in a right scrotal pneumatocele (Figure 4). There was also free air in the perineum, the perirectal space and the right lateral abdominal wal (Figures 5, 6). No free abdominal fluid or air was detected. The patient was taken to the operating room. Suprapubic cyst catheter was placed. During the perineal exam, the anorectal stump was hardly recognized among the injured tissues for it was retracted upward and ventrally making the distance between the anal canal and the perineal skin about $6 \mathrm{~cm}$ (Figure 7). A rectal washout was performed. Necrosectomy with several debridements as well as presacral irrigation were realized. The anorectal mucosa was closed at first; then the torn ends of the 


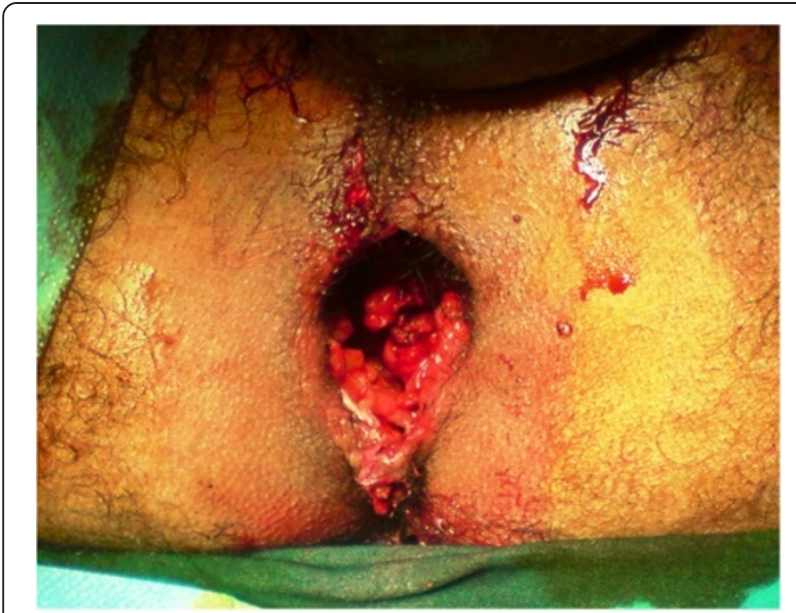

Figure 1 Inspection of the perineum showing a big loss of substance with complete avulsion of anorectal complex.

external sphincter were identified and sutured accurately. Presacral drainage was placed in the ischio rectal area by a passive drain and delbet lames (Figure 8). Finally the perineal skin was closed using good mattress sutures to build up the perineal body. A sigmoid loop colostomy was performed through an elective laparotomy in the left iliac fossa. As far as the treatment is concerned, the patient was given an antibiotic regimen consisting of ciprofloxacin and metronidazole for two weeks. The postoperative

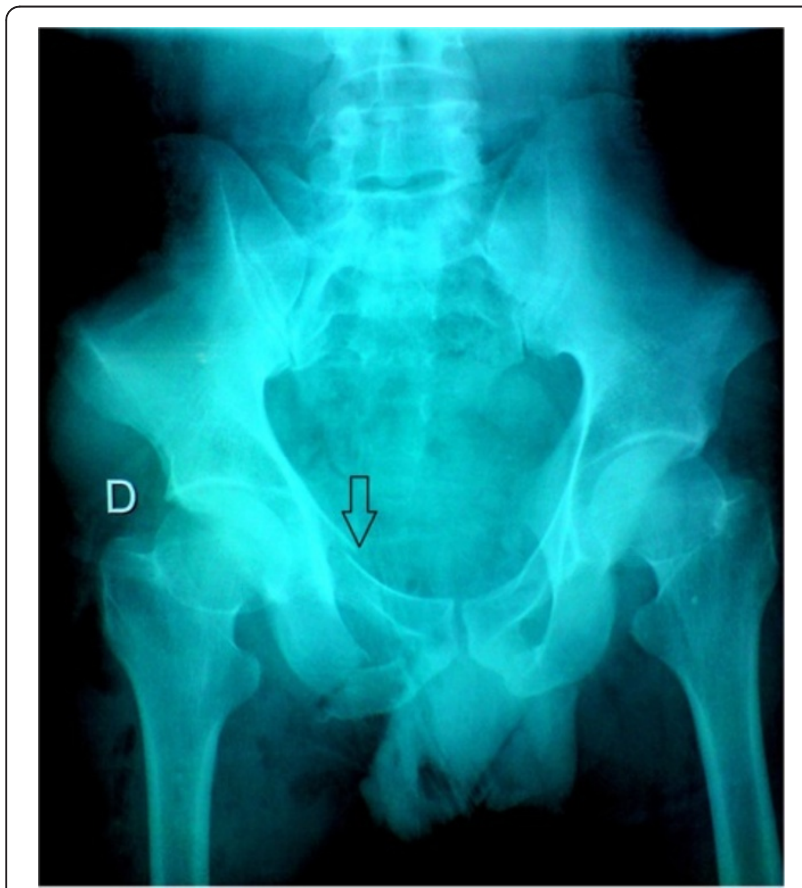

Figure 2 Pelvic X-ray showing a right ischio pubic rami fracture.

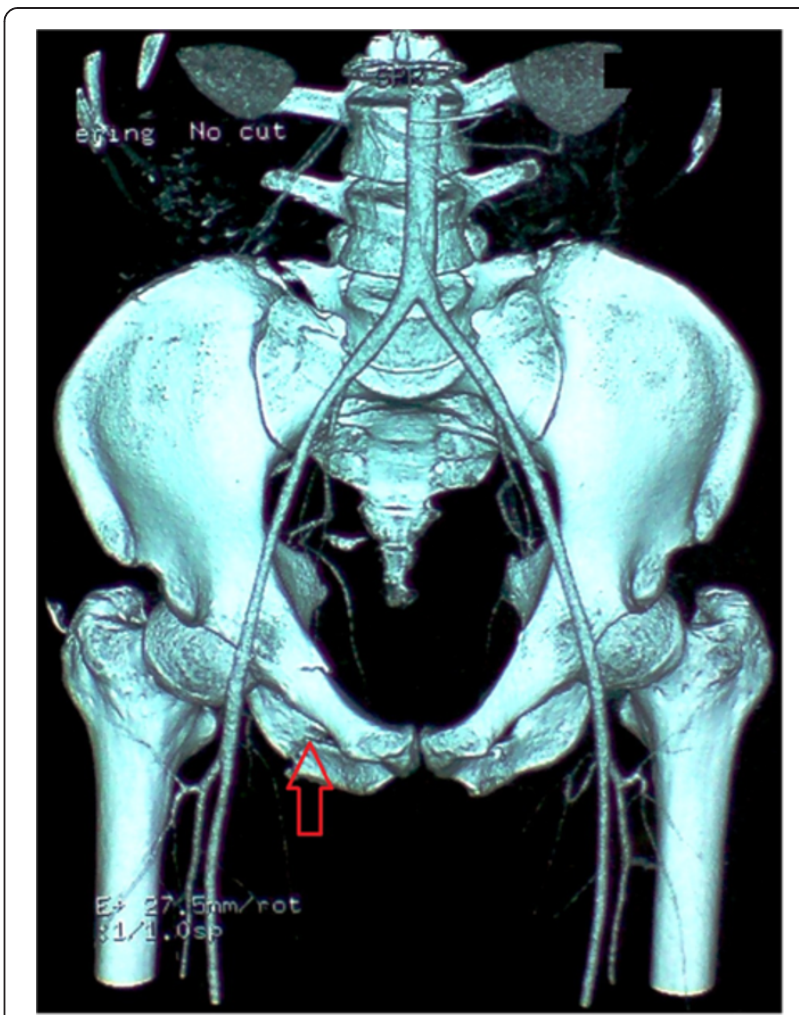

Figure 3 Computed tomography (CT) showing a right ischio pubic rami fracture.

course was unremarkable. Drainage was removed at the fifth day after surgery. Conservative treatment was undertaken for spine and rib fracture. Anorectal Manometry was performed six months after surgery. The latter did not show any physiologic dysfunction except the length

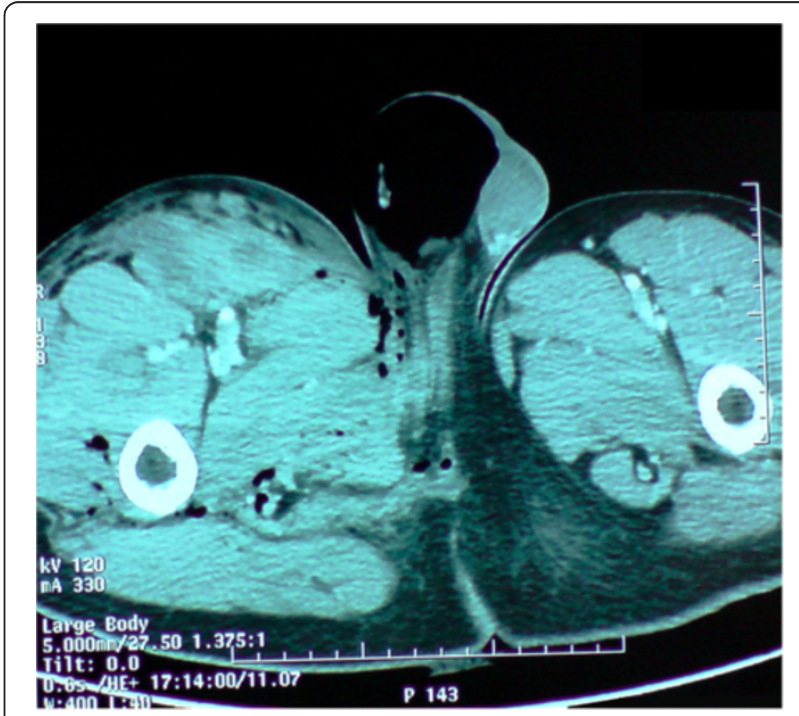

Figure $4 \mathrm{CT}$ showing a right scrotal Pneumatocele. 


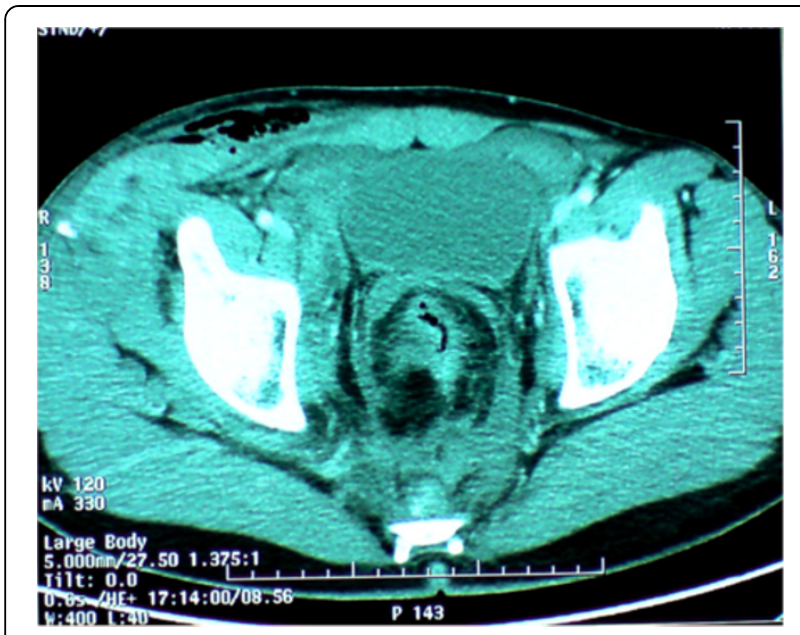

Figure 5 CT showing free air in perirectal space and in the right lateral abdominal wall.

of the anal canal which was reduced to less than $2 \mathrm{~cm}$ (Figure 9). Sigmoidostomy closure was performed seven months after the surgery. Unfortunately, the evolution was marked by anal stenosis which required iterative dilatations. Nowadays, during 9 months of follow up, the patient is free of any symptoms since the very last dilatation.

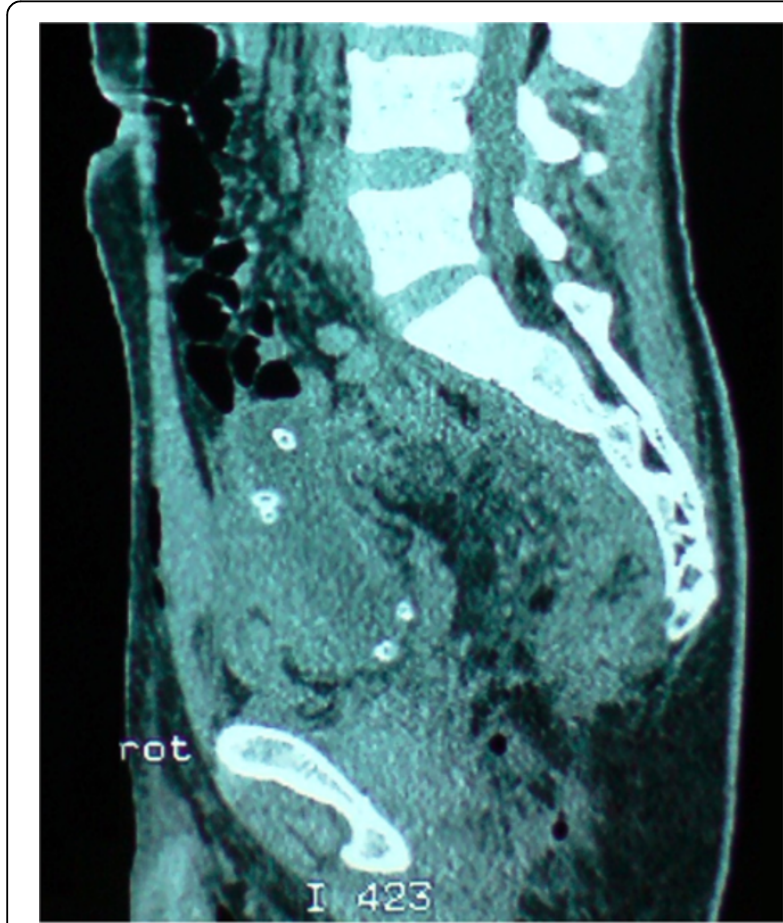

Figure 6 Coronal coupe showing the anorectal avulsion with free air in the perirectal space.

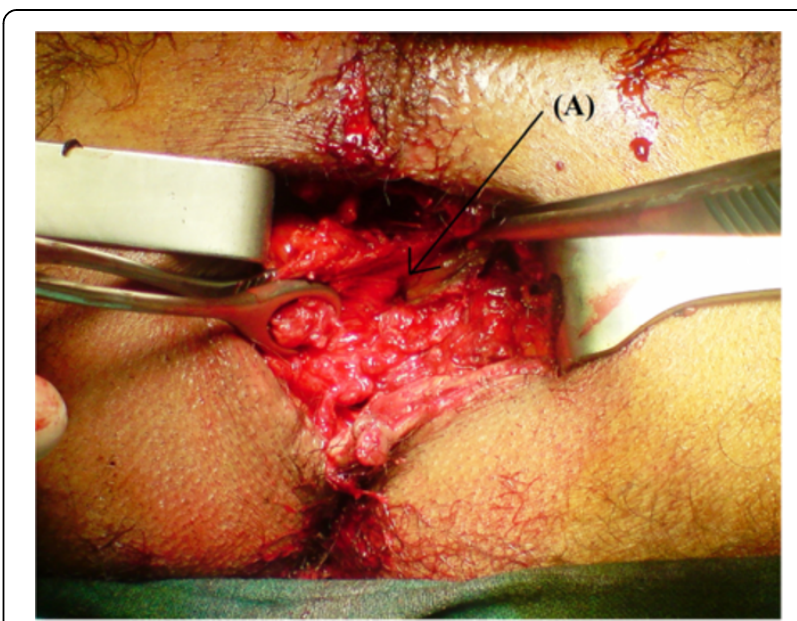

Figure 7 The perineum examination showing anorectal stump retracted upward and ventrally (A: rectal lumen).

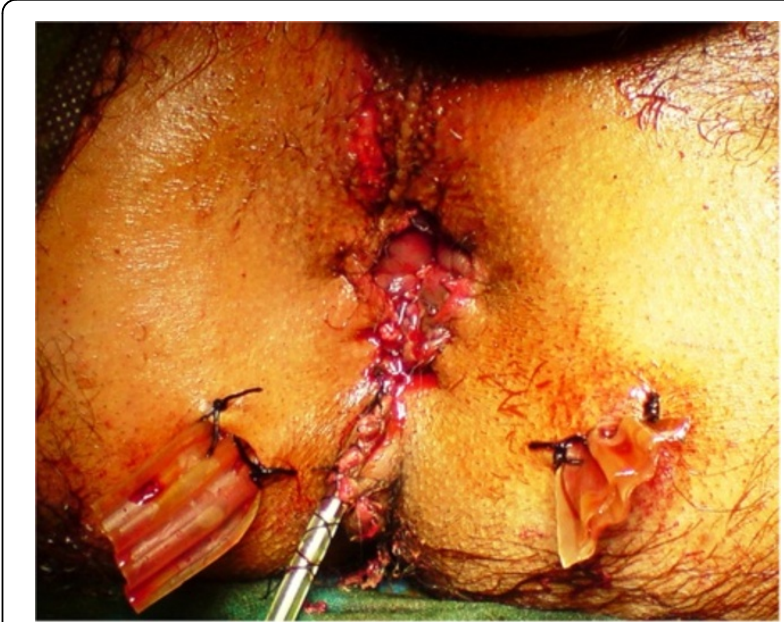

Figure 8 Perineal skin closed with presacral drainage.

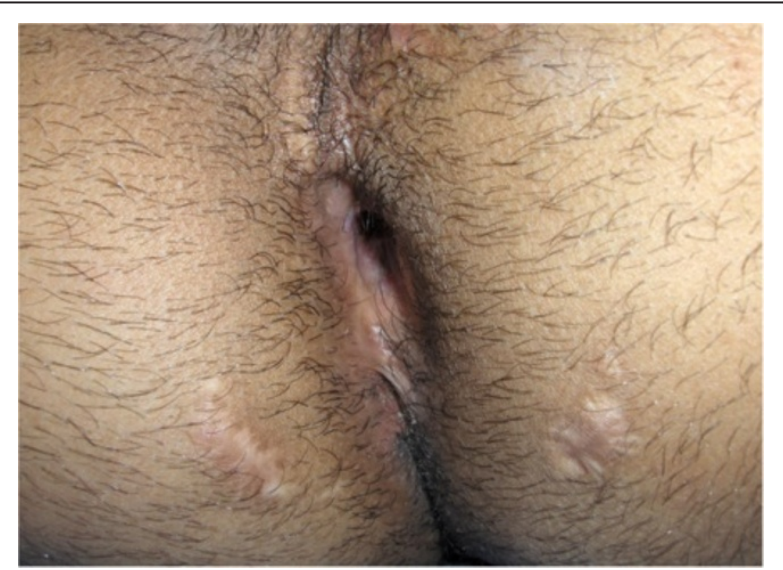

Figure 9 Final aspect of the anal margin six months after anorectal repair. 
Table 1 Reported cases of anorectal avulsion

\begin{tabular}{|c|c|c|c|}
\hline Authors & Year & Title & Management of the anorectal avulsion \\
\hline Mathieson, A. J et al. & 1965 & $\begin{array}{l}\text { Rupture of the posterior urethra and avulsion of the } \\
\text { rectum and anus as a complication of fracture of the pelvis }\end{array}$ & $\begin{array}{l}\text { Primary repair }+ \text { presacral drainage }+ \text { sigmoid } \\
\text { loop colostomy }\end{array}$ \\
\hline Sharma D. et al & 2000 & Anorectal avulsion: an unusual rectal injury & $\begin{array}{l}\text { Primary repair }+ \text { presacral drainage }+ \text { sigmoid } \\
\text { loop colostomy }\end{array}$ \\
\hline Terrosu G. et al & 2011 & Anal avulsion caused by abdominal crush injury & $\begin{array}{l}\text { Anal reimplantation }+ \text { pelvic drainage tubes }+ \\
\text { loop transverse colostomy }\end{array}$ \\
\hline Rispoli C. et al. & 2012 & Anorectal avulsion: Management of a rare rectal trauma & $\begin{array}{l}\text { Direct suture not possible sigmoid loop } \\
\text { colostomy + presacral drainage + anoperineal } \\
\text { reparation } 10 \text { weeks later }\end{array}$ \\
\hline R. M. Gomesa et al & 2013 & Anorectal avulsion: report of a rare case of rectal injury & $\begin{array}{l}\text { diverting sigmoid loop colostomy } \\
\text { (primary repair not possible) }\end{array}$ \\
\hline
\end{tabular}

\section{Discussion}

Although there are similarities between colonic injuries and rectal ones, there are also differences which are unique to the rectum. Approximately $80 \%$ of rectal injuries are attributable to firearms and less than $3 \%$ are secondary to stab or impalement etiologies. Less than $10 \%$ of rectal injuries are blunt by nature as a result of falls, motor vehicle accidents or pelvic fractures [1]. While the management of rectal injuries has changed over the last few years, optimal treatment remains a matter of great debate. The anorectal avulsion is a particular case of rectal injuries. It's a very rare rectal trauma. After reviewing the literature, we found out that the first case of post traumatic anorectal avulsion was reported in 1965 by Mathieson et al. [2]. During the following years, only few case reports were described (Table 1) [3-6]. In this kind of lesions, the anus and sphincter no longer join the perineum and are pulled upward and thus ventrally follow levator ani muscles. In addition, their treatment is controversial and not standardized [7]. A multidisciplinary approach is mandatory involving general surgeons, anesthetists and rehabilitators $[8,9]$. The main difficulties encountered when treating these lesions are: to prevent sepsis and keep good anal sphincter functions at the same time. Management strategies described in the literature include diverting sigmoidostomy, presacral drainage, direct suture repair of the rectal laceration and irrigation of the rectum. In 1989, Burch et al. [10] recommended fecal diversion and presacral drainage for rectal injury management. The primary repair of a rectal lesion should be always tried if local conditions allow it. This was the case of our patient in which direct suture was difficult to perform but was still possible. Presacral drainage is believed to prevent perirectal infections due to fecal contamination and has been used widely to reduce abscess formation in extraperitoneal rectal trauma. This evidence derives mainly by war injury [7], but some authors $[9,11,12]$ demonstrated no difference in infection rates associated with civilian rectal trauma caused by low velocity injury. Diverting colostomy has been demonstrated safe and effective in reducing the infection rate associated with rectal trauma 8 and a valid tool to perform rectal wash-out. However, in a study by Gonzales [13], fourteen patients suffering from non-destructive penetrating extraperitoneal rectal injuries were treated without fecal diversion or direct suture repair. Infectious complications didn't occur in any of these patients. Furthermore, Navsaria and colleagues concluded from their retrospective review that extraperitoneal rectal injuries caused by low-velocity penetrating trauma could be treated only by fecal diversion [9]. Although there are controversies concerning the colostomy type, the drainage method, the need for distal washout, and the need to repair the rectal wound, most trauma surgeons as it is the case with our surgical tream, would agree about the need for diversion and drainage in the management of extraperitoneal rectal injuries in addition to primary repair of rectal lesion which should always be tried if local conditions allow it $[14,15]$.

\section{Consent}

Written informed consent was obtained from the patient for publication of this Case report and any accompanying images.

\section{Competing interests}

All authors declare no competing interests.

\section{Authors' contributions}

KIM and SA participated in writing the case report and revising the draft, IT took the photos E B and KM participated in the follow up. All authors read and approved the final manuscript.

\section{Authors' information}

School of Medicine And Pharmacy of Fez, Sidi Mohammed Ben Abdellah University Department of Surgery, University hospital HASSAN II, BP: 1893: Km2.200, Route de Sidi Hrazem; FEZ 30000, MOROCCO.

\section{Acknowledgements}

The authors would like to thank the patient for his written consent and permission to present this case report. They would also like to thank Miss Ibn Majdoub Hassani Soukaina (Master : Multilingual Specialized Translation, Faculty of Arts and Humanities Sais-Fez /Sidi Mohamed Ben Abdellah University) for her help in editing and correcting this manuscript. 


\section{References}

1. Cintron JR: Colon and rectum trauma. www.fascrs.org/physicians/education/ core_subjects/2006/colon_rectal_trauma/.

2. Mathieson AJM, Mann TS: Rupture of the posterior urethra and avulsion of the rectum and anus as a complication of fracture of the pelvis. Brit J Surg 1965, 52:309.

3. Sharma D, Rahman H, Mandloi KC, Saxena A, Raina VK, Kapoor JP: Anorectal avulsion: an unusual rectal injury. Digestive Surg 2000, 17:193-194. PubMed: 10781991.

4. Terrosu G, Rossetto A, Kocjancic E, Rossitti P, Bresadola V: Anal avulsion caused by abdominal crush injury. Tech in Coloproctology 2011, 15:465-468 [PubMed: 21556880].

5. Rispoli C, Andreuccetti J, lannone L, et al: Anorectal avulsion: management of a rare rectal trauma. Int I Surg Case Rep 2012, 3:319-321.

6. Gomesa RM, Kudchadkara J, Araujob E, Gundawarc T: Anorectal avulsion: report of a rare case of rectal injury, letter to the editor. Ann Gastroenterology 2013, 26:1.

7. Velmahos GC, Gomez H, Falabella A, Demetriades D: Operative management of civilian rectal gunshot wounds: simpler is better. World J Surg 2000, 24(1):114-118. PubMed: 10594214.

8. Cleary RK, Pomerantz RA, Lampman RM: Colon and rectal injuries. Dis Colon and Rectum 2006, 49(8):1203-1222. PubMed: 16858663.

9. Navsaria PH, Edu S, Nicol AJ: Civilian extraperitoneal rectal gunshot wounds: surgical management made simpler. World J Surg 2007, 31(6):1345-1351. PubMed: 17457641.

10. Burch MD JM, Feliciano MD DV, Mattox MD KL: Colostomy and drainage for civilian rectal injuries: is that all? Ann Surg 1989, 209(5):600-610. discussion 610-1.

11. Gonzalez RP, Falimirski ME, Holevar MR: The role of presacral drainage in the management of penetrating rectal injuries. J Trauma 1998, 45(4):656-661. PubMed: 9783600.

12. Armstrong RG, Schmitt HJ Jr, Patterson LT: Combat wounds of the extraperitoneal rectum. Surgery 1973, 74:570-574. PubMed: 4729222.

13. Gonzalez RP, Phelan H 3rd, Hassan M, Ellis CN, Rodning CB: Is fecal diversion necessary for nondestructive penetrating extraperitoneal rectal injuries ? J Trauma 2006, 61(4):815-819.

14. Burch JM, Feliciano DV, Mattox KL: Colostomy and drainage for civilian rectal injuries: is that all? Ann Surg 1989, 209(5):600-610.

15. Ivatury RR, Licata J, Gunduz Y, Rao P, Stahl WM: Management options in penetrating rectal injuries. Am Surg 1991, 57(1):50-55.

\section{Submit your next manuscript to BioMed Central and take full advantage of:}

- Convenient online submission

- Thorough peer review

- No space constraints or color figure charges

- Immediate publication on acceptance

- Inclusion in PubMed, CAS, Scopus and Google Scholar

- Research which is freely available for redistribution 